\title{
Hurricane Maria: Turning a Disaster into a Real- World Learning Experience in Machine Design
}

\author{
Juan C. Morales, Ph.D., P.E. ${ }^{1}$ \\ ${ }^{1}$ Universidad del Turabo, Puerto Rico, jcmorales@suagm.edu
}

\begin{abstract}
At 6:15 a.m., on September 20, 2017, the eye of Hurricane Maria entered the town of Yabucoa, in the southeast corner of Puerto Rico, with sustained winds of $155 \mathrm{mph}$. At 2:00 pm it exited the northwestern town of Arecibo leaving behind a degree of devastation that has been regarded as the worst natural disaster on record in Puerto Rico. Upon returning to class on October 16, 2017, the author assigned a "forensic analysis" project in his Machine Design course. It consisted of analyzing a structure that failed at a bolted or welded connection due to the hurricane force winds of Maria. The topics of bolts, welds, and failure theories had been recently discussed in class. The first stage of the project consisted of showing photographs of the failed structure to the instructor to ensure that it was appropriate. The second phase consisted of handing in the written report which included the analysis of the failed structure and re-sizing the connection to avoid failure. This paper includes the following: specifications of the project; photographs of several failed structures that were analyzed by the students; free body diagrams created by the students; the expected analysis that students were required to conduct; and observations of the instructor regarding the expertise level acquired by the students while conducting this real-world project. This project is an example of how undergraduate engineering education may be enhanced, even in the face of a devastating disaster, if the instructor is willing to adapt to the particular situational characteristics of his site to innovate and engage students in transferring the knowledge learned in class to solve a real-world engineering problem.
\end{abstract}

Keywords-- Hurricane, bolts, welds, failure, adapt.

\section{INTRODUCTION}

At 6:15 a.m., on September 20, 2017, the eye of Hurricane Maria entered the town of Yabucoa, in the southeast corner of Puerto Rico, with sustained winds of $155 \mathrm{mph}$ [1] (Fig. 1). The hurricane took a northwest path across Puerto Rico that devastated the entire island (Fig. 2).

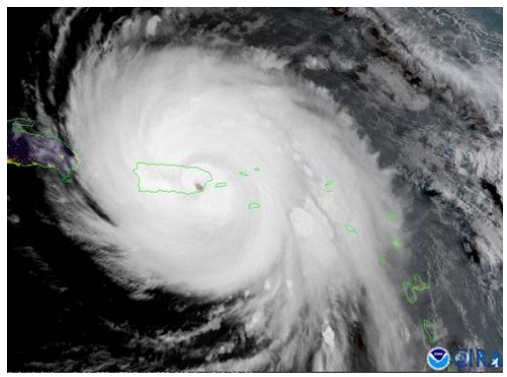

Fig. 1 Satellite photograph of Hurricane Maria as it entered Yabucoa, Puerto Rico, at 6:15 a.m. on September 20, 2017. Taken from [1].

Digital Object Identifier (DOI): http://dx.doi.org/10.18687/LACCEI2018.1.1.112 ISBN: 978-0-9993443-1-6 ISSN: $2414-6390$

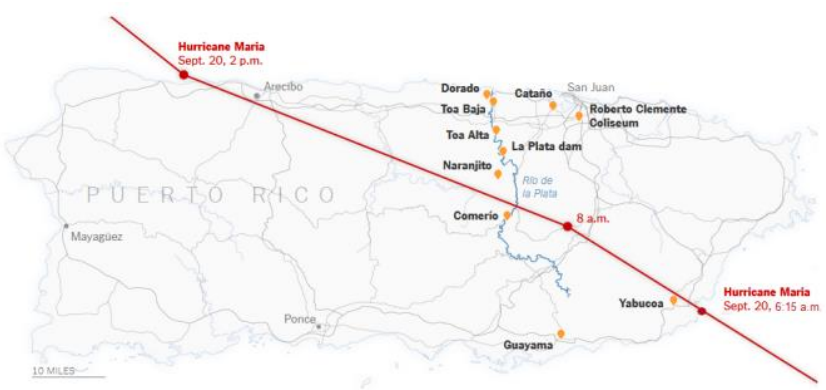

Fig. 2 Path of Hurricane Maria across Puerto Rico on September 20, 2017. Taken from [2].

Hurricane María is considered the worst natural disaster on record in Puerto Rico [3]. It is also considered the largest blackout in the history of the US [4]. Approximately $80 \%$ of the power transmission and power distribution system collapsed [5]. Reinforced concrete roofs withstood the force of the wind; however, some metal roofs (Fig. 3) and some wood roofs (Fig. 4) collapsed. Figure 4 also shows that entire wooden structures were flattened.

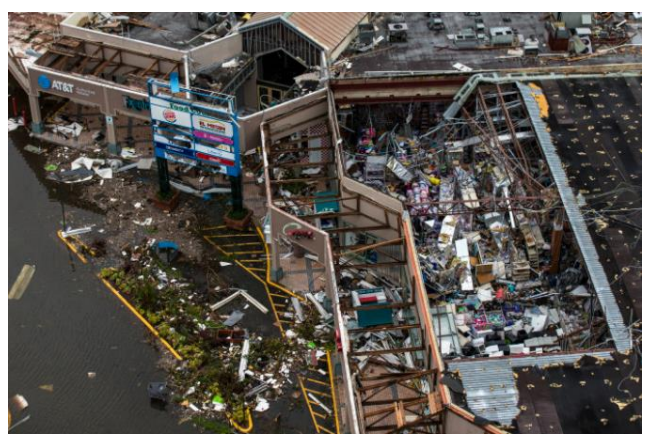

Fig. 3 Aerial view of the devastation at Palma Real Shopping Center in Humacao, a municipality on the east side of Puerto Rico. Taken from [6].

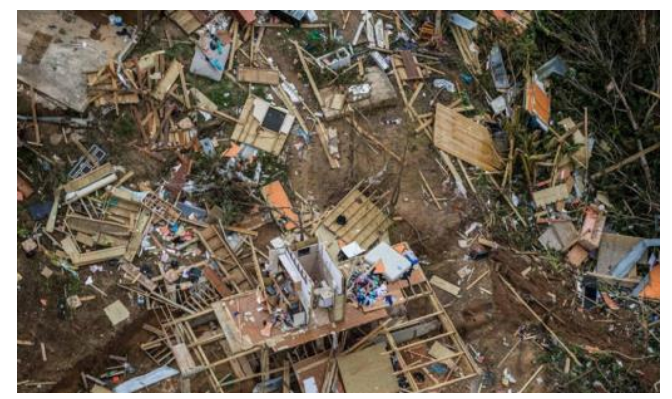

Fig. 4 Aerial view of a devastated neighbourhood in Morovis, a municipality near the center of Puerto Rico. Taken from [7].

$16^{\text {th }}$ LACCEI International Multi-Conference for Engineering, Education, and Technology: "Innovation in Education and Inclusion”, 19-21 July 2018, Lima, Peru. 
Figure 5 shows the failure of a roadway traffic sign at the "fuse plate" (Omni-Directional Breakaway System). These plates are designed to "break away with consistent, predictable behavior, regardless of the vehicle's angle of impact, thus saving lives and reducing property damage" [8]. In this case, failure was due to the unexpectedly high wind load levels instead of a vehicular impact for which it was designed.
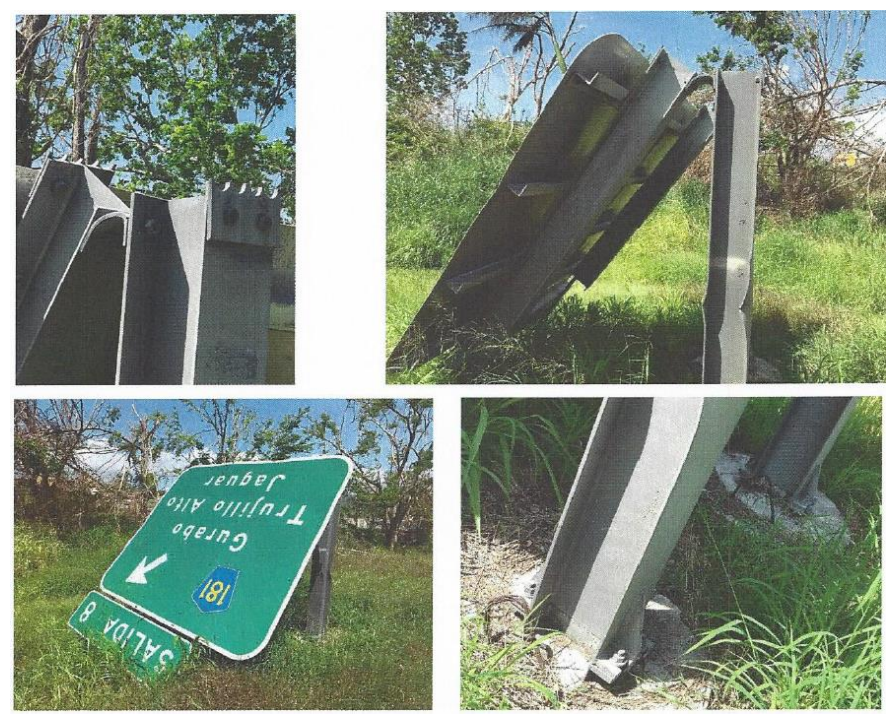

Fig. 5 Failure of traffic sign on Route 30 in the direction from Juncos to Caguas, PR. Failure occurred at the Omni-Directional Breakaway System (Fuse Plate) [8] not from vehicular impact for which it is designed, but due to the unexpectedly high wind loads.

Upon returning to class on October 16, 2017, four weeks after María, the author assigned a "forensic analysis" project in his Machine Design course. It consisted of analysing a structure that failed at a bolted or welded connection due to the hurricane force winds of Maria. The topics of bolts, welds, and failure theories had been recently discussed in class. Students had to select failed structures such as the one shown in Fig. 5, which classify as "mechanical design" (mechanical engineering discipline) rather than those shown in Fig. 3 or Fig. 4 which classify as "structural design" (civil engineering discipline). The specifications for the project are presented in the next section.

\section{PROJECT SPECIFICATIONS}

SAFETY FIRST! Do not risk injury during this exercise. If the structure is in a non-accessible place or, if it is accessible and it is difficult to take measurements, you may assume some of the required information (see below).

\section{Objective}

To practice forensic analysis of a failed structure. After you analyze the failure, you shall suggest a design (sizing) modification so that it would not have failed. This exercise will provide you a real-world example to practice the failure models and sizing concepts discussed in class.

\section{Description}

Part 1 Due date: Wednesday, November 8, 2017. In class. Select a structure that failed due to the winds of hurricane María (September 20, 2017). Pay particular attention to structures that failed at a bolted connection. The bolt or the plate must have failed. You may also select a welded connection if you cannot find a case with a bolted connection (use weld sizing concepts instead of bolt sizing). Discuss the case with the professor at the end of class. Bring a photograph of the structure. If you miss the deadline, please send an email to the professor (jcmorales@suagm.edu) with a photograph and a short description. This part of the project is to ensure that you select an appropriate case before embarking on the analysis.

Part 2 Due date: Wednesday, December 13, 2017

Hand in your report.

\section{Report specifications}

Part A. Description of the case. Include the following:

1. Photograph(s)

2. Location of the structure. Include the road and kilometer, and the town and barrio, if applicable.

3. Explanation of how the structure failed, in your own words.

Part B. Known facts. In this section you will only include factual information. You must measure the structure to determine, for example, the diameter of the bolts, the grade of the bolt (if it has markings on the bolt head), the thickness of the plate in the connection, the dimensions of the structure, etc. Remember, SAFETY FIRST!

Part C. Assumptions. In this section you will include required information that you do not know as a fact, for example, the yield strength of the material, the most probable wind speed (gust) at the location, any relevant dimensions that you were not able to measure due to inaccessibility or risk to injury, etc. Anything that you cannot measure (state as a fact) you must include as an assumption and clearly declare it as an assumption. In a real forensic case that goes to court, although you still would need to make some assumptions, you would most probably have to test the material to determine the yield strength and carry out a deeper analysis to state more facts. However, in this case the objective is to practice the class concepts, so you do not have to go in deeper details. Above all, do not risk your safety! Remember, SAFETY FIRST!

Part D. Wind model. As mentioned in class you must search fluid textbooks and the internet to develop the wind model that relates wind speed to wind force. This will provide 
you with the opportunity to engage in an activity that promotes a "life-long learning experience", e.g., learn things on your own. This is an expected outcome of your undergraduate engineering education.

Part E. Free Body Diagram. Include the wind force, the location of the wind force, any other forces that are relevant, and the reactions at the point of interest. Sketch it with orthographic views. You may need two different orthographic views in order to capture all the forces in the real structure. You may also add an isometric projection, if you wish, but orthographic views are required to present the dimensions appropriately as they relate to the analysis of the free body diagram.

Part F. Forensic Analysis. Conduct the forensic analysis to show that the structure fails. You will be using the same models and equations used in class. You may have to take corrosion into account, if present, as a reduction in actual loadbearing area (e.g., the part becomes thinner because some of the material has been lost due to corrosion). You will also have the opportunity to vary parameters to see how they affect the situation.

Part G. Resize the structure so that it does not fail. In this part, determine the required size. It may be a larger bolt diameter, a thicker plate, or a larger fillet weld. Select a safety factor based on section 6.12 of the textbook and "defend" your selection.

Part H. Additional Information. Include in this part any information that you may find important to discuss. However, be brief, because the emphasis of this project is to practice the class concepts, e.g., failure models and sizing calculations.

Part I. Final Remarks / Conclusions. Add a concluding section with any final remarks that you wish to include.

Report length. The expected report length will be 5 to 10 pages.

Report language. You must write the report in English. This will give you an opportunity to practice it. English is the world-wide language of engineering. You must get used to writing and reading in English since you will need it in your professional career.

Title Page with Company Name. The report must have a title page. Imagine that you are a consultant and that you have your own company. Select a name for your imaginary company and include it in the title page.

\section{FAILED STRUCTURES}

The following figures are a representative sample of the cases evaluated by the students in their projects. Due to space limitations, only a sample is shown. It was not a group project so each student in class worked individually with a case.
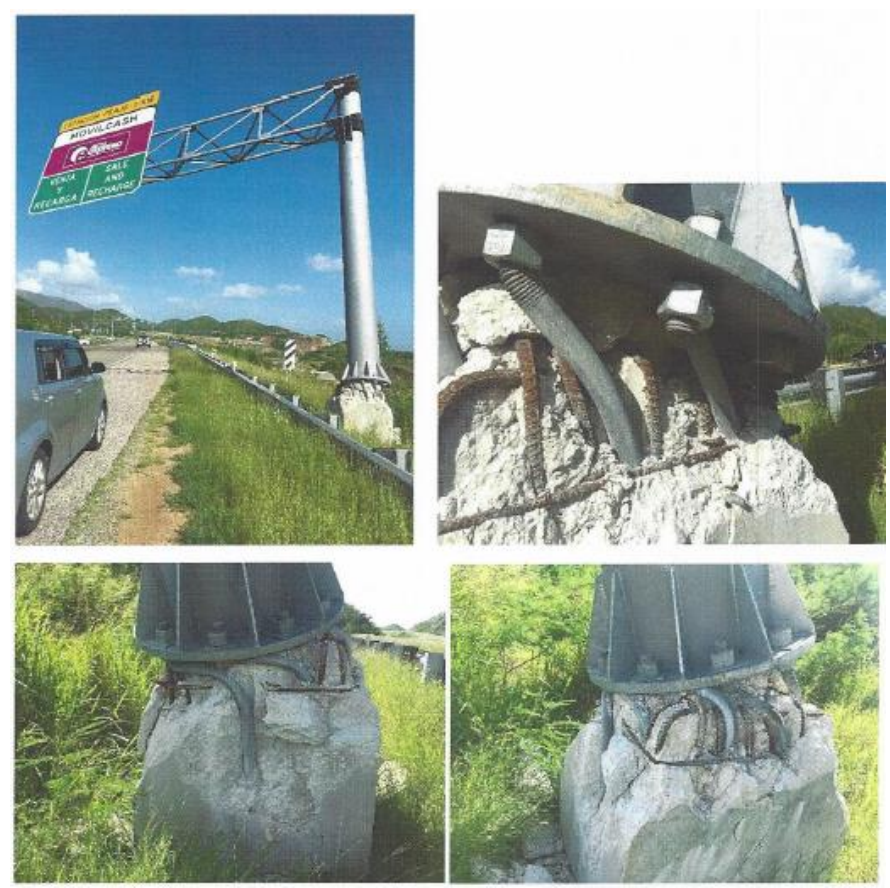

Fig. 6 Failure of an expressway sign on Highway 53, km. 6.1 in Guayama, PR. Failure occurred at the base due to a combination of torsion, overturning moment, and direct shear loads. Only the bolts were analysed.

The concrete base was assumed to have resisted prior to bolt failure since concrete analysis/design is outside of the scope of the course.
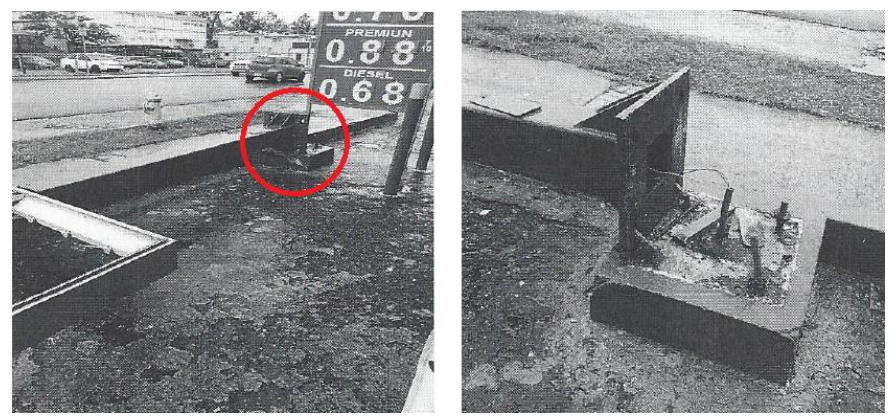

Fig. 7 Failure of a gas station sign in San Lorenzo, PR. Failure occurred at the baseplate due to a combination of the overturning moment and direct shear loads. In this case the holes were too large for the size of the bolts used and they "pulled out". This type of failure (pull-out due to dimensioning miscalculations) was identified in four projects. 


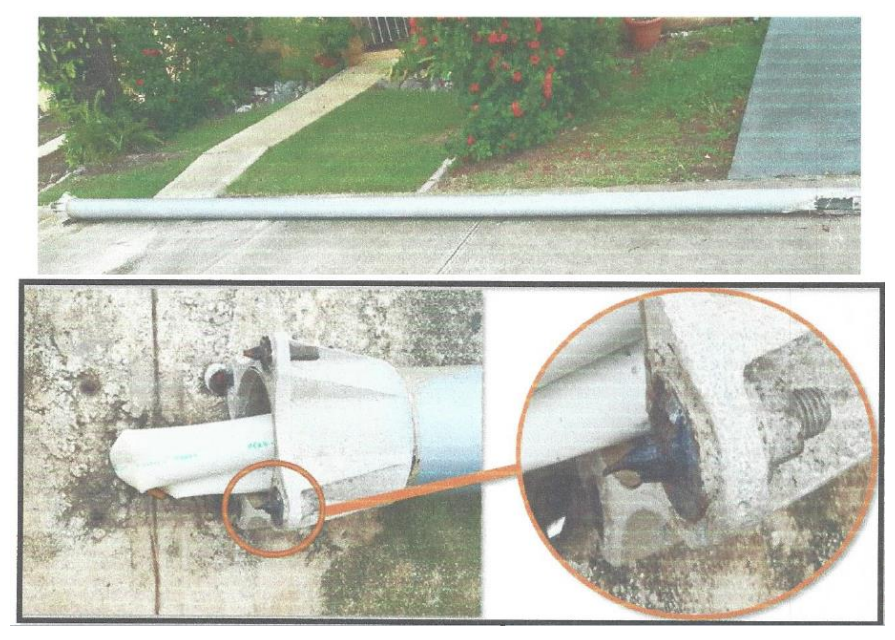

Fig. 8 Failure of a light pole at Ave. Arterial B, San Juan, PR. Failure occurred at the base due to a combination of the overturning moment and direct shear loads. Extreme corrosion is evident in the bolts and contributed heavily in the failure.
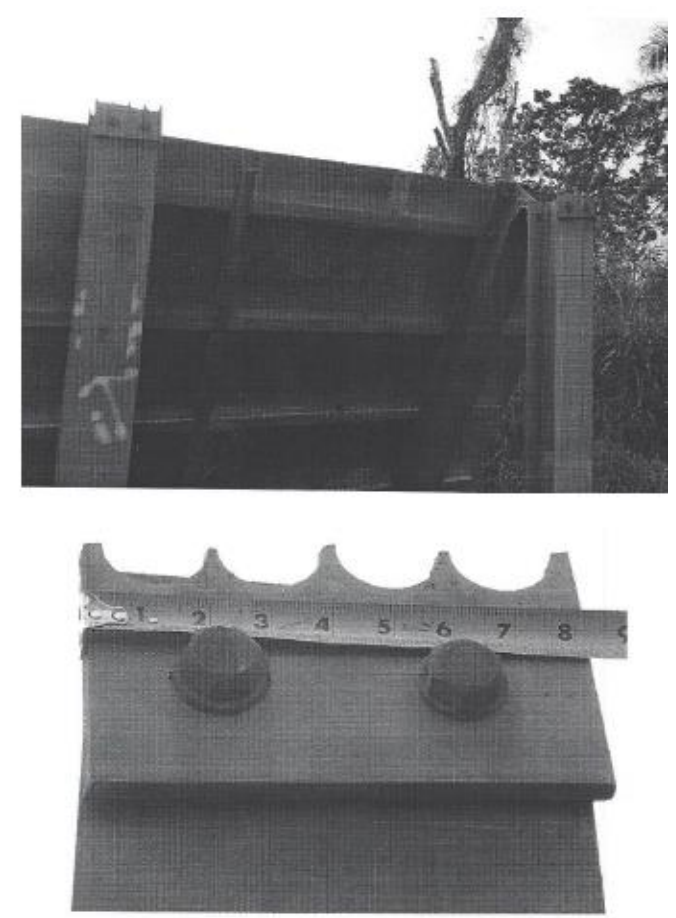

Fig. 9 Failure of a traffic sign on Route 30, Juncos, PR. Failure occurred at the fuse plate (like Fig. 5) due to a combination of the overturning moment and direct shear loads. If the wind loads are modified in existing structural codes, these fuse plates will need to be redesigned.
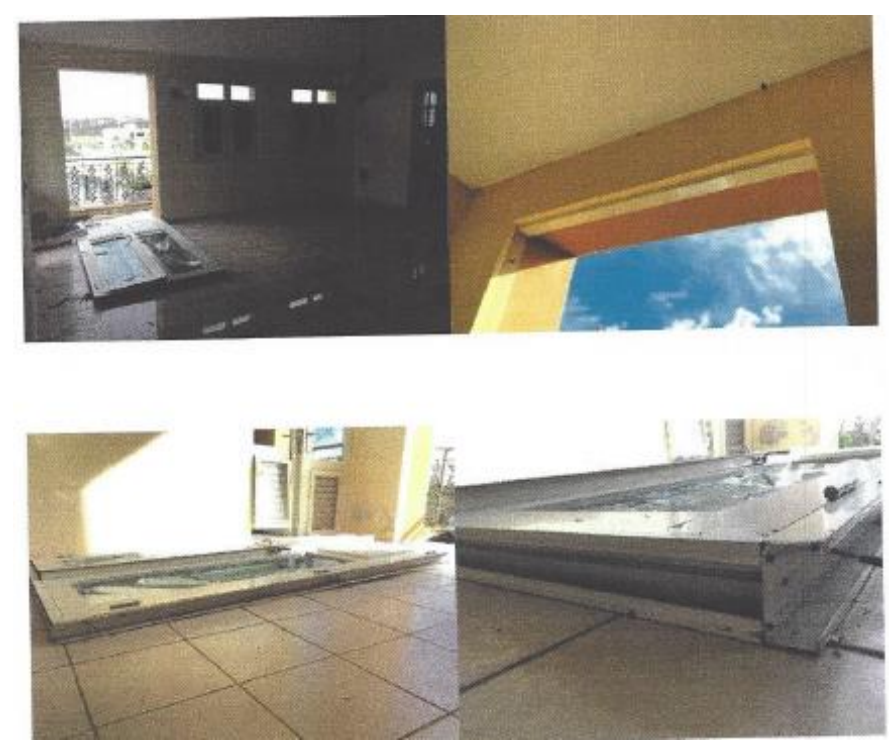

Fig. 10 Failure of the frame anchors of a residential front door located in Las Piedras, PR, due to the direct shear load. Many doors and windows failed during hurricane Maria due to an insufficient number of anchors.
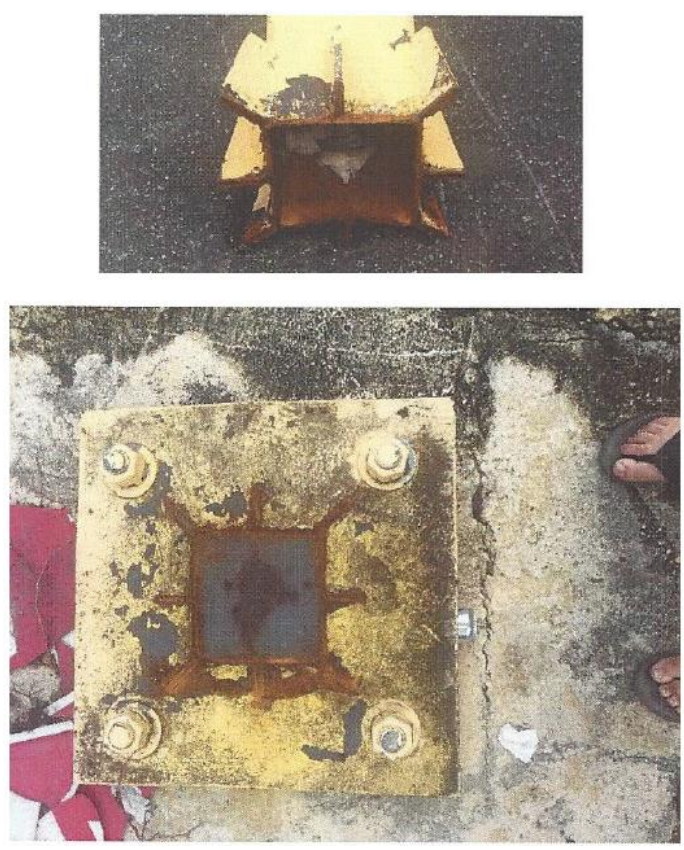

Fig. 11 Failure of a sign post in Guaynabo, PR. The bolted plate was able to withstand the force of the wind but not the weld which failed by a combination of the overturning moment and direct shear loads. Corrosion seems to have played an effect as well. 


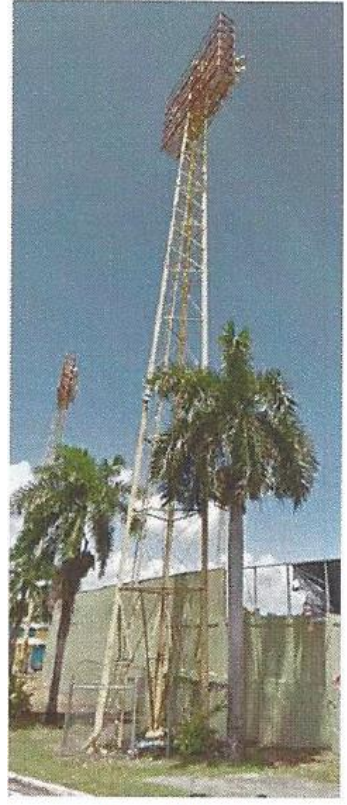

Before Maria

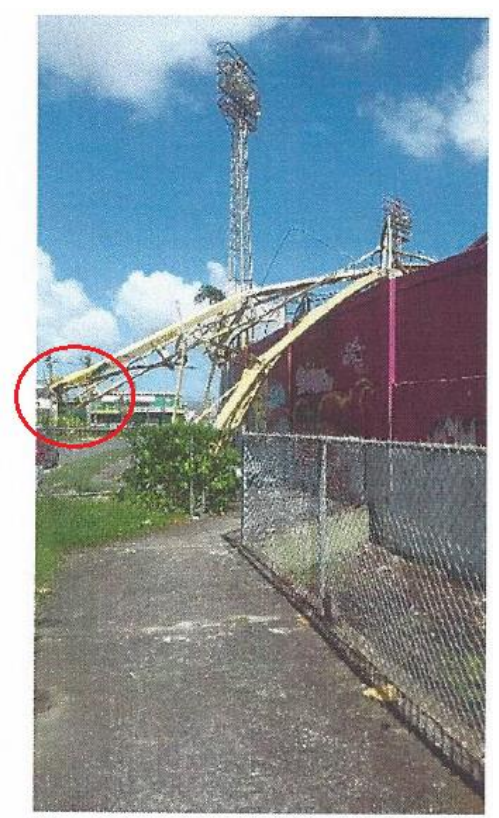

After Maria
Fig. 12 Failure of a light tower at the Ildefonso Solá Morales baseball stadium in Caguas, PR. The three legs of the tower have a tripod geometry. The baseplate bolts of the windward leg fractured due to the overturning moment and direct shear loads and the tower overturned (see red circle for location of the baseplate).

\section{DATA AND ASSUMPTIONS}

Students understood the importance of separating facts from assumed values. Fig. 13 includes the data, and Fig. 14 includes the assumptions, written by one of the students.

\section{Part B. Known facts.}

The following data are the fact that were measured by hand with a metric ruler.

- Diameter of the bolts $=1 \frac{1 / 4 "}{4}$

- Grade of the bolts = Grade A-307A

- Carbon steel bolts of 36,000psi

- Thickness of the base $=1 / 4$ "

- Length of the carbon steel base $=1 \mathrm{ft}$ and 1 " which is equal to $1.083 \mathrm{ft}$

- Length of the border of the base to the bolt $=1 / 2$ "

- Length (Height) of the lightning pole $=14 \mathrm{ft}$

- Diameter of top of the lightning pole $=10$ "

- Diameter of bottom of the lightning pole $=9 "$

- Projected area of the lightning pole $=1595.992 \mathrm{pulg}^{\wedge} 2 \sim 1596 \mathrm{pulg}^{\wedge} 2$

- Vertical long holder of the triangle structure $=2 \mathrm{ft}$ and $2 \frac{1}{2}$ " which is $2.21 \mathrm{ft}$

- Vertical short holder of the triangle structure $=4$ "

- Diameter of the vertical holders $=3 "$

- Diameter of both legs of the triangle $=4 \frac{1}{2} "$

Fig. 13 "Facts" of the case as presented by one of the students in class.

\section{Part C. Assumptions. Exeellent section.}

- The material used for the pole is some type of steel, but given that the specific material was not found it is assumed that is a galvanized steel because that is the material often used on the traffic light poles for strength and corrosion-resistance. The minimum yield strength of this material used for the poles is $450 \mathrm{MPa}$ and a tensile strength between 510 to $600 \mathrm{MPa}$.

- The material for the base and the bolts is carbon steel, but because there is an uncertainty on how much of carbon are in the alloy, the minimum tensile strength a carbon steel alloy, will have is $36,000 \mathrm{psi}$ or $248,310,496.6 \mathrm{MPa}$.

- The highest hurricane Maria wind speed at Caguas was 188 miles per hour according to the paper "El Vocero". The temperature was at 25 Celsius.

- Given the high wind speed, it's assumed that the wind flow is turbulent $\left(\operatorname{Re}>10^{\wedge} 4\right)$.

- Because the top diameter and the bottom diameter of the lightning pole is not the same , (there's a difference of 1"), the area of the pole was calculated by the use of Bretshneider's formula and the projected area resulted to be almost the same as if it were assumed that the top and bottom diameter were constant by putting the average diameter which is 9.5 ". For purposes of this project, the diameter will be assumed to be constant of 9.5 " through the whole lightning pole.

- Every component of the structure is symmetrical to ease the calculation of the centroid of each component.

- The drag coefficient were calculated with turbulent flow with a table retrieved from CheggStudy.

- The next figure shows a legend of the structure to indicate what measures were assumed. The measures were obtained and assumed to be true with the app called "ImageMeter" which works by applying a known measure of the structure and with that, it gives an average measure that it's needed by working with scales. The table shows the measures.

Fig. 14 "Assumptions" of the case as presented by one of the students in class.

\section{WIND MODEL}

The students asked several questions during class discussions regarding the wind model. Due to the many uncertainties during a hurricane, it was decided to assume that the wind velocity profile remained constant as a function of height. The drag force formula was used to calculate the force of the wind as a function of velocity. It is given by:

$$
\mathrm{F}_{\mathrm{D}}=0.5 \rho \mathrm{C}_{\mathrm{D}} \mathrm{AV} \mathrm{V}^{2}
$$

where, $\rho=$ density of the fluid, $C_{D}=$ drag coefficient of the structure, $\mathrm{A}$ is the projected area of the structure, and $\mathrm{V}=$ the speed of the fluid (hurricane wind speed).

The students were instructed to investigate on their own the value that they would select for the drag coefficient $C_{D}$ and to use simplifying assumptions regarding the geometry of the structure, e.g., idealize it as a plate, or a cylinder, or other similar geometries available in the literature, for the sake of obtaining a value for $\mathrm{C}_{\mathrm{D}}$.

\section{FREE BODY DIAGRAMS}

There is probably not one machine design professor who wishes that their students showed more skill in drawing free body diagrams, including the textbook author Robert Juvinall, who makes similar remarks of his University of Michigan students in the preface of his textbook [9].

In this project, the most typical error was not including the unknown reaction forces and moment at the location of the cut. They always included the reactions in the equilibrium equation but only some students included them on the free body diagram. Fig. 15 shows a free body diagram in which the 
moment $M$ was included but the reaction forces $R_{x}$ and $R_{y}$ were not. Instead, the student included the resulting normal stress $\left(\sigma_{\mathrm{y}}\right)$ due to the overturning moment and the direct shear stress $\left(\tau_{x y}\right)$ due to the direct shear load (wind force). The figure shows notes included by the author to the student.
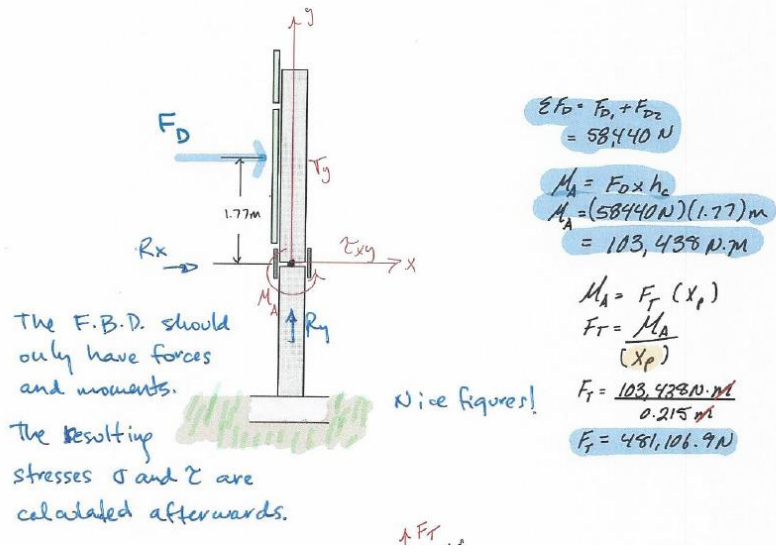

$\mu_{A}=F_{T}\left(x_{\rho}\right)$ $F_{T}=\frac{\mu_{A}}{\left(x_{\rho}\right)}$ $F_{T}=\frac{103,438 \mathrm{~N} \cdot \mathrm{m}}{0.215 \mathrm{~m}}$ $F_{T}=481,106.9 \mathrm{~N}$

tresses $\sigma$ and $\tau$ ar

Fig. 15 Free body diagram of roadway sign drawn by one of the students. The cut is made at the appropriate location (fuse plate) but does not include the reactions Rx nor Ry. The figure includes comments by the author.

Fig. 16 shows another free body diagram where the student did a good job of locating the wind force at several points in the system (traffic light structure) but did not explicitly indicate the reactions at the base of the structure where it failed.
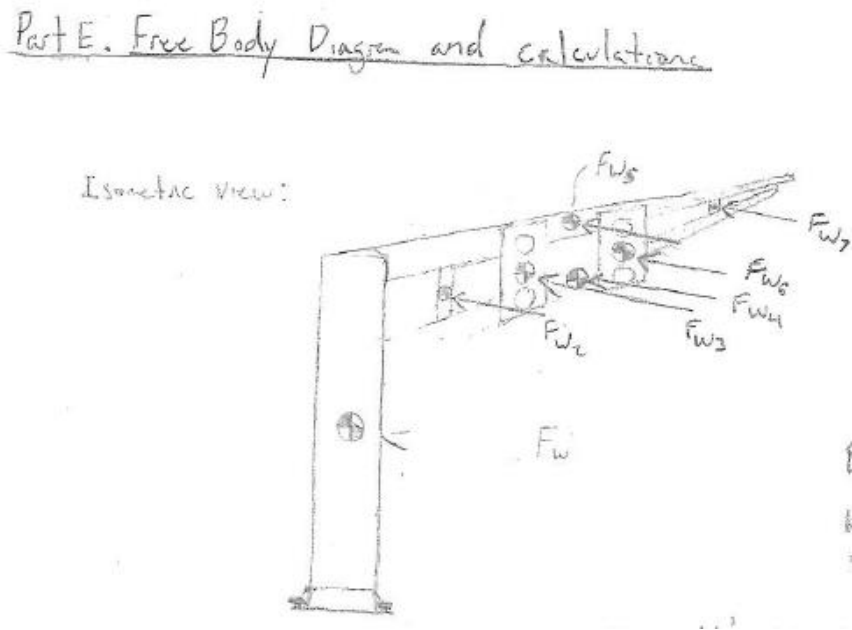

Fig. 16 Free body diagram of a traffic light structure. The student did a good job of locating the wind forces applied to the structure but did not explicitly include the reactions at the base (but included in the equations).

Fig. 17 includes a free body diagram typical of bolted connections in which the overturning moment is reacted by an equivalent force couple at the bolts.
Solving for the bolt force allows the student to calculate a normal stress applied to the bolt.

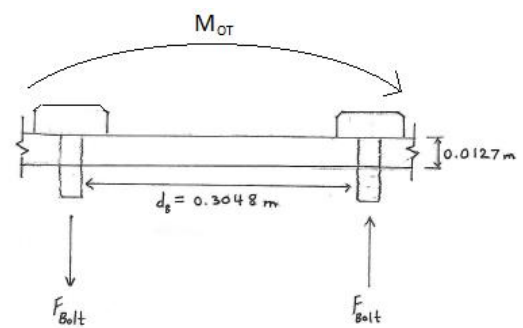

Fig. 17 Free body diagram of a typical bolted baseplate. The overturning moment is reacted as a force couple by the bolts, one in tension and the other one in compression. This FBD is required to calculate the force in each bolt which is then used to calculate the normal stress in the bolt.

To calculate the force in the bolt, set up an equilibrium equation between the overturning moment and the force couple that reacts it at the bolts:

$$
\begin{aligned}
& \mathrm{M}_{\text {OVERTURNING }}=\left(\mathrm{F}_{\text {BOLT }}\right)\left(\mathrm{d}_{\text {BOLT }}\right) \\
& \mathrm{F}_{\text {BOLT }}=M_{\text {OVERTURNING }} / \mathrm{d}_{\text {BOLT }}
\end{aligned}
$$

\section{FAILURE THEORIES}

The philosophy behind the various classical failure theories of static loading is that whatever is responsible for failure in the standard tensile test will also be responsible for failure under all other conditions of static loading [9].

The Maximum Shear Stress theory ( $\tau_{\operatorname{MAX}}$ theory) postulates that failure during the tensile test occurs because the material is limited by its inherent capacity to resist shear stress. Therefore, the theory predicts that under any conditions of static loading, failure will occur if, and only if, it exceeds its $\tau_{\mathrm{MAX}}$ capacity. If the material is ductile, and yielding is set as the failure criterion, the maximum shear stress capacity in a tension test is equal to $\tau_{\mathrm{MAX}}=\mathrm{S}_{\mathrm{y}} / 2$, as may be seen in the Mohr's circle shown in Fig. 18.
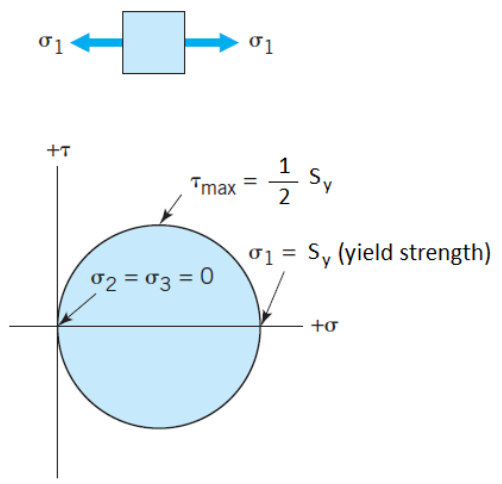

Fig. 18 Mohr's circle representation of a uniaxial tension test. For a ductile material, the failure criterion is the onset of yielding $\left(\mathrm{S}_{\mathrm{y}}\right)$. Taken from [9] and adapted.

$16^{\text {th }}$ LACCEI International Multi-Conference for Engineering, Education, and Technology: "Innovation in Education and Inclusion”, 19-21 July 2018, Lima, Peru. 
A safety factor (S.F.) may be included as a strengthreduction factor in the design so the $\tau_{\mathrm{MAX}}$ failure criterion for a ductile material becomes,

$$
\tau_{M A X}=\frac{S_{y}}{2} \frac{1}{S . F}
$$

To determine the maximum shear stress in any loading case it is first necessary to determine the critical point in the structure (where it will most probably fail) and establish the state of stress at the point, as shown in Fig. 19.

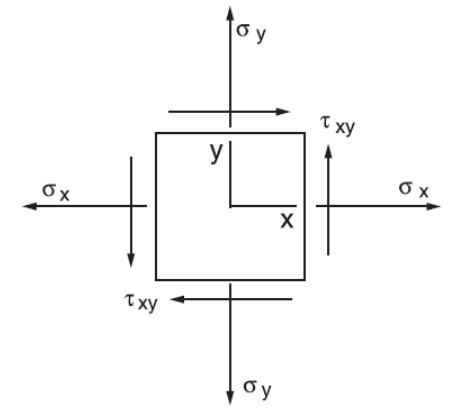

Fig. 19 Typical state of biaxial stress at a point with all the stress components shown in their positive sense.

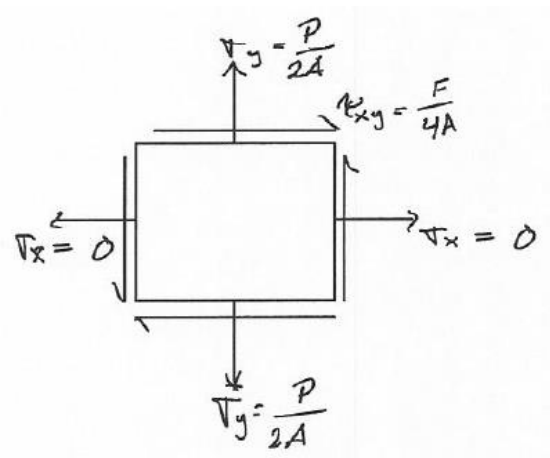

Fig. 20 State of biaxial stress at the fuse plate (see Fig. 5). The normal stress in the y direction $\left(\sigma_{\mathrm{y}}\right)$ is generated by the overturning moment which is reacted as a couple by the fuse plates; the normal stress in the $\mathrm{x}$ direction is zero since there are no loads in that direction $\left(\sigma_{\mathrm{x}}=0\right)$; and the shear stress $\left(\tau_{\mathrm{xy}}\right)$ is due to the direct shear load that must be resisted horizontally (the wind force).

Once the biaxial state of stress is determined, the maximum shear stress can be obtained by following the procedure shown in Fig. 21 [10].

The procedure in Fig. 21 uses Mohr's circle as an instrument to visualize the principal stresses and to easily calculate them as a function of the location of the center of the Mohr's circle and its radius. This methodology is taught to students as it is available in the handbook used in the
Fundamentals of Engineering (FE) exam required for licensure as a professional engineer.

The circle drawn with the center on the normal stress (horizontal) axis with center, $C$, and radius, $R$, where

$$
C=\frac{\sigma_{x}+\sigma_{y}}{2}, \quad R=\sqrt{\left(\frac{\sigma_{x}-\sigma_{y}}{2}\right)^{2}+\tau_{x y}^{2}}
$$

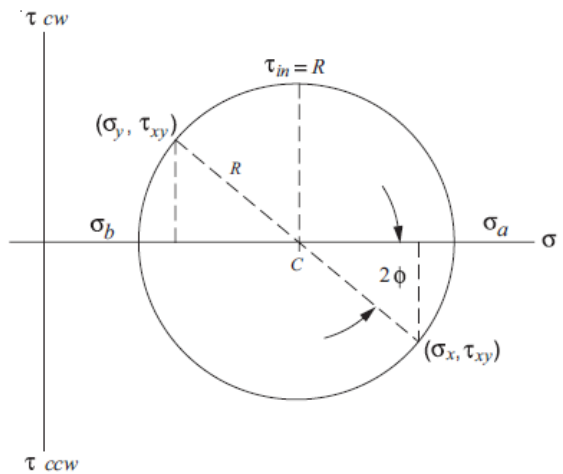

The principal stresses are then: $\sigma_{a}=C+R, \sigma_{b}=C-R, \sigma_{c}=0$

algebraically largest $=\sigma_{1}$, algebraically smallest $=\sigma_{3}$, other $=\sigma_{2}$

The maximum shear stress is $\tau_{\max }=\frac{\sigma_{1}-\sigma_{3}}{2}$

Fig. 21 Procedure to calculate the maximum shear stress at a point in a structure. Mohr's circle is used as an instrument to visualize the principal stresses and to easily calculate them. This procedure was taken from [10]

Some students used the bolt size (or weld size) information to analyze the strength of the design and show that it was inadequate to resist the hurricane wind loads of Maria. Then they proceeded to resize the connection.

Other students used the wind loads and the configuration of the connection to size the bolts or the welds and then compared that value to the actual ones. In this manner they could prove in one step that the connection was inadequate and provide an adequate bolt or weld size.

\section{CONCLUSIONS}

This project is an example of how undergraduate engineering education may be enhanced, even in the face of a devastating disaster, if the instructor is willing to adapt to the particular situational characteristics of his site to innovate and engage students in transferring the knowledge learned in class to solve a real-world engineering problem.

The transfer of knowledge, particularly to a real-world engineering problem, is the quintessential outcome one expects from our engineering graduates.

It may be concluded that a successful experience of this kind requires, on average, three meetings with the students. The first meeting was to ensure that the selected case was appropriate (phase 1). During this first meeting many issues

16 $^{\text {th }}$ LACCEI International Multi-Conference for Engineering, Education, and Technology: "Innovation in Education and Inclusion", 19-21 July 2018, Lima, Peru. 
were addressed; for example, for the case shown in Fig. 6, the student was instructed to ignore the failure of the concrete base since the mechanics of concrete failure was beyond the scope of the course. The student assumed that failure had started in the steel bolts while the concrete was assumed to have failed at a later stage during the catastrophic failure progression. Issues like this one were discussed with the entire group during class. Students were reminded that the failure mode was the onset of yielding, i.e., yielding begins while the structure is still standing upright. The fact that the wind load continued to be applied to the structure is what caused the failure to progress to the catastrophic result shown in Fig. 6.

During Phase 2 of the project, two additional meetings, on average, took place with each student to discuss progress with the forensic analysis and with the redesign of the connection. In these meetings, the students required assistance in the following:

1. Identifying the most probable load path through the connection that led to failure. It was not always evidently clear.

2. Setting up the free-body diagram that correctly modelled the most probable load path.

3. Idealization of the structure to be able to carry out a machine design analysis with classical hand calculations.

4. Clearly identifying the assumptions that were required to conduct the analysis.

5. Ensuring that all the steps identified in the specifications of the report were conducted.

The author believes that these time-intensive, one-on-one meetings with the students, were crucial to achieve the purpose of the project. If students are left on their own to figure out all the issues, they would have had much difficulty in appropriately transferring the knowledge of the course to the real-world problem. Textbook problems tend to always be clear and neat while real-world problems tend to be messy and disorganized. It is noted that it was the students themselves who initiated the meetings with the author as they started encountering difficulties during the analysis, particularly identifying the failure progression and the load path through the connection. It became clear that the more willing the professor is in investing time during this phase, the better the experience will be for the students.

The experience also turned out to be very interesting for the author since it provided an excellent opportunity to analyze several structures. It also provided the author with the opportunity to interact more closely with the students and to get to know them better. It was a very gratifying experience for all.

\section{ACKNOWLEDGMENTS}

The author acknowledges the excellent work that students produced in their projects and, above all, their excellent attitude.
Regarding their attitude, a clear indicator is that attendance was $100 \%$ on the first day we met after Maria, on October 16, 2017. The university still did not have power. We relied on opening the classroom doors and windows for ventilation. For illumination we relied on sunlight.

A captivating anecdote of that first day we met after hurricane María, is that sunlight ended halfway into the class, which was scheduled from 5:00-6:30 pm. At around 5:45 $\mathrm{pm}$, while I was in the middle of answering a question about failure theories, I realized that I could not see the whiteboard clearly because the sun had already set. At that point, and without announcing it to the students, I decided to bring out my flashlight from one of my cargo-pants pockets to illuminate the whiteboard. As I continued with my explanation, flashlight in hand, I thought that students would start complaining and "invite" me to finish the class early due to the scarce visibility. On the contrary, students started bringing out their own flashlights to assist me in illuminating the whiteboard. They continued engaged in the explanation and the ensuing discussion. We continued with flashlights for an additional 45 minutes and successfully completed the first class after hurricane María.

I think that I will never forget that moment and the tremendous attitude shown by my students. The project itself showed the capacity of turning a disaster into a real-world learning experience. But that moment, with flashlights in hand, showed our capacity to adapt and to continue forward in our commitment to education, even in the direst of circumstances.

\section{REFERENCES}

[1] Hurricane María entering Puerto Rico. https://www.nasa.gov/feature/goddard/2017/maria-atlantic-ocean Retrieved January 17, 2018.

[2] Path of Hurricane Maria across Puerto Rico. https://www.nytimes.com/interactive/2017/09/18/world/americas/hurrica ne-maria-tracking-map.html Retrieved January 17, 2018.

[3] https://en.wikipedia.org/wiki/Hurricane_Maria. Retrieved January 17, 2018.

[4] http://edition.cnn.com/2017/10/26/us/puerto-rico-poweroutage/index.html. Retrieved January 17, 2018.

[5] https://www.elnuevodia.com/noticias/locales/nota/elplandelcuerpodeinge nierosesarreglarnorenovar-2363709/. Retrieved January 17, 2018.

[6] https://www.denverpost.com/2017/10/01/storm-ravaged-caribbeaneyeing-solar-power/. Retrieved January 17, 2018.

[7] http://www.nationalgeographic.com.au/nature/exclusive-aerial-photoscapture-puerto-ricos-devastation.aspx. Retrieved January 17, 2018.

[8] Omni-Directional Breakaway System (Fuse Plate). https://www.transpo.com/roads-highways-rh/safety-products/breakawaysupports/break-safe. Retrieved January 30, 2018.

[9] Juvinall, RC. and Marshek, K.M.. Fundamentals of Machine Component Design, $5^{\text {th }}$ ed., John Wiley and Sons. 2011.

[10] NCEES Reference Handbook, version 9.2, Retrieved January 21, 2018 http://www.engineering.uco.edu/ aabuabed/index_files/FE_Handbook.pd $\underline{f}$

$16^{\text {th }}$ LACCEI International Multi-Conference for Engineering, Education, and Technology: "Innovation in Education and Inclusion”, 19-21 July 2018, Lima, Peru. 